OPEN ACCESS

Edited by:

Rita de Cassia Marqueti,

University of Brasilia, Brazil

Reviewed by:

Christina Karatzaferi,

University of Thessaly, Greece

Ivo Neto,

University of Brasilia, Brazil

${ }^{*}$ Correspondence: Jens Rithamer Jakobsen

Jens.rithamer.jakobsen@regionh.dk;

jensjakobsendk@gmail.com

Specialty section:

This article was submitted to

Striated Muscle Physiology,

a section of the journal

Frontiers in Physiology

Received: 30 November 2020

Accepted: 15 February 2021

Published: 26 March 2021

Citation:

Jakobsen JR and Krogsgaard MR

(2021) The Myotendinous

Junction-A Vulnerable Companion

in Sports. A Narrative Review.

Front. Physiol. 12:635561.

doi: 10.3389/fphys.2021.635561

\section{The Myotendinous Junction-A Vulnerable Companion in Sports. A Narrative Review}

\author{
Jens Rithamer Jakobsen* and Michael Rindom Krogsgaard \\ Section of Sports Traumatology, M51, A Part of IOC Research Center, Bispebjerg and Frederiksberg Hospital, Copenhagen \\ University Hospital, Copenhagen, Denmark
}

The incidence of strain injuries continues to be high in many popular sports, especially hamstring strain injuries in football, despite a documented important effect of eccentric exercise to prevent strains. Studies investigating the anatomical properties of these injuries in humans are sparse. The majority of strains are seen at the interface between muscle fibers and tendon: the myotendinous junction (MTJ). It has a unique morphology with a highly folded muscle membrane filled with invaginations of collagen fibrils from the tendon, establishing an increased area of force transmission between muscle and tendon. There is a very high rate of remodeling of the muscle cells approaching the MTJ, but little is known about how the tissue adapts to exercise and which structural changes heavy eccentric exercise may introduce. This review summarizes the current knowledge about the anatomy, composition and adaptability of the MTJ, and discusses reasons why strain injuries can be prevented by eccentric exercise.

Keywords: myotendinous junction, strain injury, Nordic Hamstring, Eccentric exercise, force transmission, injury prevention, hamstring strain injury

\section{INTRODUCTION}

The transition zone between skeletal muscle and tendon, the myotendinous junction (MTJ), has a key role in being the structure where muscle fibers interact with tendon. During muscle activity and especially during high effort exercise, large forces are transmitted from muscle fibers to the tendon through the MTJ (Huijing, 1999). The ability to transmit force is optimized by a unique architecture of the muscle fibers at their termination at the MTJ (Knudsen et al., 2015). Despite this, force applied to the MTJ can be so extensive, especially during eccentric loading, that strain injuries occur (Garrett, 1996). These are among the most frequent injuries in many popular sports (Orchard and Seward, 2002). There is intense research to develop models to predict who are at risk to be afflicted by these injuries, how to prevent them and on what the best rehabilitation strategy is, once they have occurred. Strangely, there has been a negligible focus on the ultrastructure of the human MTJ, which is where many injuries occur, and how the MTJ adapts to training and inactivity (Mjolsnes et al., 2004; Petersen et al., 2011; Seagrave et al., 2014; Van Der Horst et al., 2015). Even though such basic science studies would be highly relevant to understand the clinical aspects of strain injuries, the human studies have mainly explored the ultrastructure of the MTJ. The plasticity of the MTJ in relation to loading and unloading which is of particular interest for clinicians working 
with strain injuries, have been studied in animals exposed to running or weightlessness, and these activities are not easily transformable to human exercise situations.

The aim of this article is to review current knowledge about the ultrastructure and composition of the MTJ with focus on the human MTJ, strain injuries, with particular focus on hamstring strain injuries, and possible strategies for prevention. Also, the review suggests directions for research related to the MTJ in the future.

\section{METHODOLOGY}

The literature for this review was found by searching PubMed. To identify studies regarding the structure of the MTJ and strain injuries, the following strategy was used:

(Myotendinous junction OR Muscle-tendon interface) AND (ultrastructure OR morphology OR force transmission OR strain injury OR hamstring strain injury).

To identify studies addressing strain injuries and prevention of hamstring strain injuries the following strategy was used: [(Muscle strain injury) OR (Hamstring strain injury)] AND (Injury prevention) NOT (sprain) NOT (tendinopathy) NOT (ACL).

All studies identified with the search strategies were manually evaluated by reading either the title, abstract or full article. In addition to articles identified from the search strategy, we used articles that we knew from our research on the MTJ. Studies regarding the neonatal or developing MTJ was not included in this review, and it has been reviewed thoroughly by others (Charvet et al., 2011, 2012; Valdivia et al., 2017).

The identified literature describing the basic structures of the MTJ and the adaptations at the MTJ following exercise seemed slightly dated. In contrast, there are many recent clinical investigations describing the preventive effects of various training protocols on the incidence of strain injuries, and the Nordic hamstring protocol is by far the most documented.

\section{ULTRASTRUCTURE}

The ultrastructure of the MTJ in animals, show finger-like processes from tendon, protruding into muscle at the contact area between the two tissues (Trotter et al., 1985). By 3-D EM of the human MTJ these processes have been shown to be foldings of tendon, protruding into invaginations of the muscle membrane (Figure 1; Knudsen et al., 2015). This ultrastructure increases the contact area between muscle and tendon, making it possible for the contractile force from the myofibrils to be transmitted through a larger area. This results in a reduced amount of stress and higher breaking strength of the MTJ (Eisenberg and Milton, 1984; Tidball, 1991). In a model of frog semitendinosus MTJ it has been calculated that these protrusions increase the surface area by 13.2 times compared to a smooth cone-shaped junction (Tidball, 1984). Also, the folding structure increases the angle of force transmission, and consequently a high proportion of force is transmitted through shear stress (Tidball, 1983). For chicken latissimus dorsi muscles it has been reported that the surface area of the MTJ in type II muscle fibers is $40 \%$ larger compared to type I fibers (Trotter and Baca, 1987). Type II muscles are capable of producing higher forces than type I fibers, and it is good strategy that the transmission surface is larger in relation to type II fibers. However, whether this difference in surface area between muscle fiber types also exists in humans is not known. The correlation between muscle fiber type and risk of strain injury has been suggested previously (Garrett et al., 1984). In contrast to rats and mice, where many muscles are primarily composed of either type I or type II fibers, human muscles consist of varying proportions of both fiber types and in the most frequently injured muscles in humans, the hamstrings, rectus femoris and gastrocnemius, type II fibers are dominant (Polgar et al., 1973). Whether the surface area in the MTJ from these muscles is larger by development or can be increased through training, is unknown.

The plasticity (ability to adapt) of the MTJ to various loads has mainly been investigated in animals (summarized in Table 1) where most of the studies are slightly dated, and there is only one study investigating the human MTJ (Kannus et al., 1992; Tidball and Quan, 1992; Zamora et al., 1995; Roffino et al., 2006, 1998; Kojima et al., 2008; Palma et al., 2011; Curzi et al., 2012, 2013, 2016; Rissatto Sierra et al., 2018; Jacob et al., 2019; Pimentel et al., 2020). The protocols for the animal studies are very inhomogeneous, as the animals have been subjected to different regimens for loading and unloading, and as various species and muscles have been analyzed, which makes it impossible to draw one conclusion from these studies. In addition, the method to measure the area of the MTJ interface varies between studies (Table 1).

Overall, in the rat MTJ there is evidence of an increasing complexity of the foldings as response to a period of intensified loading (by running), with higher number of branches and longer foldings (Kojima et al., 2008; Curzi et al., 2013, 2016). This indicates that the MTJ adapts to load by increasing the junctional interface. Higher intensity of loading provided as fast running has shown significantly greater increases in the surface area of the MTJ compared to a lighter intensity running intervention (Curzi et al., 2016). This positive effect of load was not seen on the length and thickness of the evaginations when compared in a model of ladder climbing and loaded ladder climbing (Pimentel et al., 2020). It would be relevant in future studies to implement various training variables, such as intensity, and study the effect on the surface area of the MTJ.

There are varying results on the effect of unloading (Table 1). The rat MTJ shows a smaller interface between muscle and tendon in groups after 3 weeks of unloading compared to control groups, and this is effected by shortening of the foldings. The surface area of the MTJ is almost $50 \%$ in the unloading groups, independent of muscle fiber type (Kannus et al., 1992), and similar changes have been recorded after only 4 days of weightlessness during a spaceflight (Tidball and Quan, 1992). Contrary, the length of foldings in MTJs from rats that had been exposed to a 14 days spaceflight and weightlessness was 58\% higher than in controls (Roffino et al., 1998). 


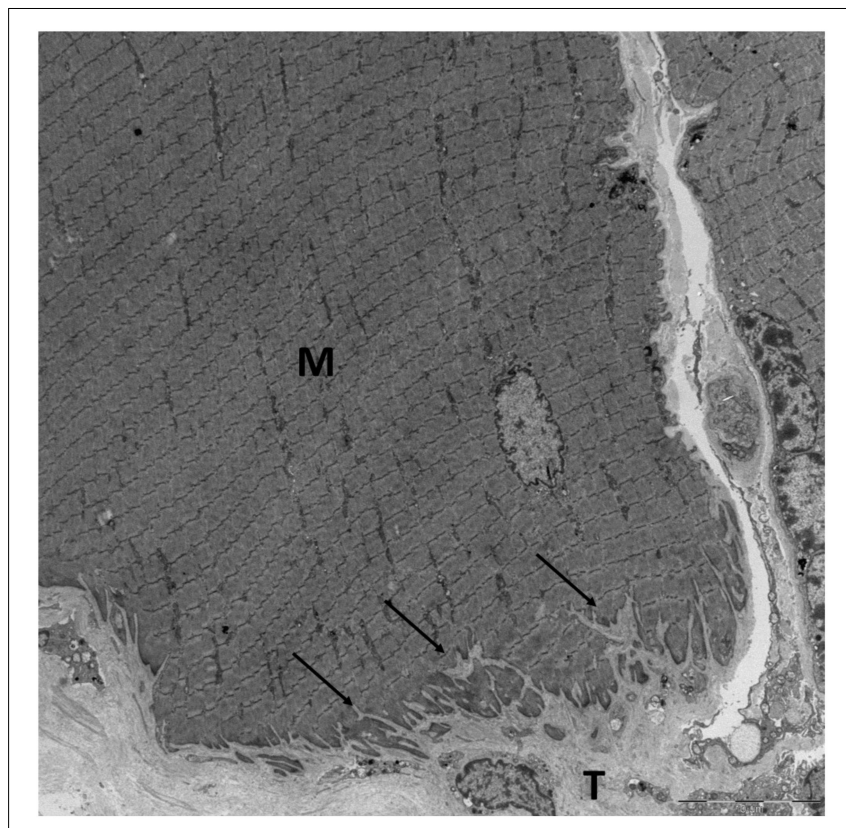

FIGURE 1 | The MTJ of a human semitendinosus muscle fiber viewed with EM. The protrusions (arrows) from the tendon ( $T$ ) into the muscle fiber (M) increase the contact area between the muscle and tendon. Scale bar is $10 \mu \mathrm{m}$. Image by Andreas B. Knudsen, made at the Centre for Integrated Microscopy (CFIM) at the Panum Institute in Copenhagen, Denmark, used by permission.

These conflicting results may be explained by the method to calculate the surface area, namely as the ratio between the length of foldings at the MTJ and muscle fiber diameter. It is reasonable to assume that 14 days of weightlessness results in a higher degree of muscle fiber atrophy than 4 days, and if the length of the foldings remain constant, the calculated surface area increases with increasing length of loading. This may explain the surprising higher surface area of MTJ in rats after 14 days space flight.

The effect of unloading on the surface area of the MTJ in humans has been studied in 12 elderly patients who had a femoral amputation after being bed based for a long time period due to chronic disease. When compared to specimens from legs of 3 young persons who had acute amputations after accidents, there was a reduction in the surface area of the MTJs in the bed based patients (Palma et al., 2011). However, it is not known to which degree this was a result of unloading, the age difference or the chronic disease conditions.

Reduction of the surface area between muscle and tendon as a consequence of unloading can theoretically weaken the MTJ by making it less capable to transmit load - and thereby more susceptible to injuries. This may be the reason why elite soccer players, who had less than 10 training sessions before they participated in a competitive match after an injury period, had an increased risk of a subsequent injury (Bengtsson et al., 2019). For every additional training session before returning to match, the odds for an injury were $7 \%$ lower. This indicates that after a period of reduced activity, loading of the hamstrings MTJ should be implemented in training as soon as possible before full activity is resumed.

\section{COMPOSITION OF THE MTJ}

Through invagination of the muscle fiber membrane the cytoskeleton from the muscle fibers is in contact with the extracellular matrix (ECM) which connects muscle to tendon: the cytoskeletal connection-from actin to the ECM (Henderson et al., 2017). In brief, intramuscular bundles of actin filaments from the last A-band attaches at the cytoplasmic side of the sarcolemma to either dystrophin, which connects with the transmembrane dystroglycan complex, or the vinculin-talinintegrin complex (Shear and Bloch, 1985). These complexes penetrate the sarcolemma and attach actin on the intracellular side with laminin and collagen fibrils on the other, providing the path for force transmission from muscle fiber to tendon. Dystrophin and integrins therefore represent the physical structure through which force is transmitted. Knockout studies on mice have shown that absence of either dystrophin or integrin severely reduces the strength of muscle and increases its susceptibility to injuries (Guo et al., 2006). Interestingly, it has been observed, that by increasing the levels of integrin, the negative effects from the knockout of dystrophin are largely compensated (Hakim et al., 2013). This finding is clinically relevant for patients with Duchennes muscular dystrophy, since absence of dystrophin is the main pathogenesis of the disease. However, in addition to impairing the force transmission through the MTJ, called the linear force transmission pathway as it occurs in line with the sarcomeres, absence of dystrophin also affects lateral force transmission (Ramaswamy et al., 2011). Through this pathway force is transmitted from the contractile elements in the muscle fiber laterally through costameres to the endomysium (Pardo et al., 1983; Ervasti, 2003). There are junctions between the endomysium and perimysium, suggesting that lateral force transmission might occur through these junctions to the perimysium, which continues as endotenon in the tendon (Passerieux et al., 2006, 2007). It is not known if the lateral force transmission is changed by loading and unloading. However, an increase in lateral instead of linear force transmission through the MTJ would relieve the MTJ of some of the extra stress related to increasing training load.

It has been demonstrated by confocal imaging of MTJ that collagen type XXII is exclusively present in the foldings immediately on the tendon side of the muscle fiber membrane (Figures 2, 3; Jakobsen et al., 2017). The specific function of this collagen is not known, but knockout studies in zebrafish have shown a reduced potential for force transmission as well as an increased risk of ruptures at the MTJ when collagen XXII is absent (Charvet et al., 2013). Collagen XXII is located at tissue junctions and is not found elsewhere in skeletal muscle (Koch et al., 2004). Therefore, it is a marker to identify the MTJ, which is helpful, for instance in wide field imaging. Next to collagen XXII on the tendon side of the MTJ is a variety of collagens, including the smaller FACIT (Fibril Associated Collagen with Interrupted Triple Helices) collagens XII and XIV 
TABLE 1 | Studies describing the effects of loading and unloading on the surface area of the MTJ with a description of species used, muscles and muscle fiber types and the method used for measurements.

\begin{tabular}{|c|c|c|c|c|c|}
\hline \multicolumn{6}{|c|}{ Studies describing the effect of increased load on the MTJ } \\
\hline $\begin{array}{l}\text { Author, } \\
\text { year,species }\end{array}$ & $\begin{array}{l}\text { Sample Size pr } \\
\text { Group }\end{array}$ & $\begin{array}{l}\text { Muscles/dominant } \\
\text { fiber type }\end{array}$ & Intervention & Method of measurement & Results \\
\hline Kojima,2008,rat & 5 & $\begin{array}{l}\text { Gastrocnemius/ I } \\
\text { Tibialis Ant./II }\end{array}$ & Running & $\begin{array}{l}\text { Branching of fingers Angle } \\
\text { of branching }\end{array}$ & $\uparrow$ \\
\hline Curzi. 2012,rat & 6 & Gastrocnemius/I EDL/II & Running & Branching of fingers & $\uparrow$ \\
\hline Curzi. 2016. rat & 3 & EDL/II & Running & $\begin{array}{l}\text { Interface } \\
\text { length/baseline(IL/B ratio) }\end{array}$ & $\uparrow$ \\
\hline Sierra. 2018. rat & 3 & Soleus/l & Swimming & $\begin{array}{l}\text { Length and thickness of } \\
\text { invaginations and } \\
\text { evaginations }\end{array}$ & $\uparrow$ \\
\hline Jacob. 2019. rat & 5 & Sternomastoid/ll & Swimming & $\mathrm{IL} / \mathrm{B}$ & \\
\hline Neto J, 2020 rat & 10 & Plantaris/II & Loaded ladder climb & $\begin{array}{l}\text { Length and thickness of } \\
\text { invaginations and } \\
\text { evaginations }\end{array}$ & $\uparrow$ \\
\hline \multicolumn{6}{|c|}{ Studies describing the effect of unloading the MTJ } \\
\hline $\begin{array}{l}\text { Author, } \\
\text { year,species }\end{array}$ & $\begin{array}{l}\text { Sample Size pr } \\
\text { Group }\end{array}$ & $\begin{array}{l}\text { Muscles/dominant } \\
\text { fiber type }\end{array}$ & Intervention & Method of measurement & Results \\
\hline Kannus, 1992. rat & 8 & $\begin{array}{l}\text { Gastrocnemius/II } \\
\text { Soleus/l }\end{array}$ & $\begin{array}{l}\text { Immobilization } 1 \text { and } 3 \\
\text { weeks }\end{array}$ & $\begin{array}{l}\text { Length of surface area in } \\
\text { relation to muscle fiber } \\
\text { diameter }\end{array}$ & $\downarrow$ \\
\hline Tidball 1992. rat & 6 & Plantaris/ll & Space flight -4 davs & Folding factor & $\downarrow$ \\
\hline Zamora. 1995. rat & $\begin{array}{l}2 \\
5\end{array}$ & Soleus/I Plantaris/ll & $\begin{array}{l}\text { Limb suspension for } 8,18 \\
\text { and } 29 \text { davs } \\
\text { Space flight } 14 \text { days }\end{array}$ & No quantification & $\begin{array}{l}\text { Only minor changes } \\
\text { observed in Plantar is } \\
\text { MTJ's. } \\
\text { thinning and lengthening } \\
\text { of the foldings at MTJ of } \\
\text { Soleus MTJ s }\end{array}$ \\
\hline Roffino, 1998. rat & 8 & Soleus/l & Space flight 14 days & $\begin{array}{l}\text { IL B ratio-named } \\
\text { normalized interface values } \\
\text { by the authors. }\end{array}$ & $\uparrow$ \\
\hline $\begin{array}{l}\text { Roffino, } \\
\text { 2006.monkey }\end{array}$ & 2 & Soleus/I +II & Space flight 14 days & No qualification & - \\
\hline $\begin{array}{l}\text { de Palma, } \\
\text { 2011,human }\end{array}$ & $\begin{array}{l}12 \\
\text { Unloaded } \\
3 \text { controls }\end{array}$ & Gastrocnemius/ I+II & $\begin{array}{l}\text { Bed rest (mean } 60 \text { months) } \\
\text { in chronic diseased patients }\end{array}$ & $\begin{array}{l}\text { Length of surface area } \\
\mathrm{n} \text { relation to muscle } \\
\text { fiber diameter }\end{array}$ & $\downarrow$ \\
\hline Curzi,2013,rat & 4 & Plantaris/II & Unloading & $\begin{array}{l}\text { IL/B ratio Length of primary } \\
\text { digits Brancing of fingers }\end{array}$ & $\downarrow$ \\
\hline
\end{tabular}

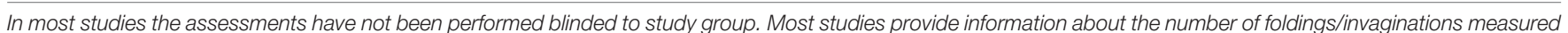

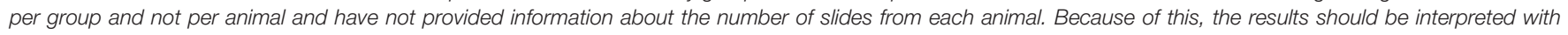
some caution. Arrows indicate whether an increase $(\uparrow)$ or a decrease $(\downarrow)$ in the measures was reported. EDL, Extensor Digitorum Longus.

(Figure 3; Jakobsen et al., 2017). Future studies must determine the functions of these various collagens.

\section{EFFECTS OF EXERCISE ON THE COMPOSITION OF THE MTJ}

There is incomplete knowledge about the effects of exercise on the composition and ultrastructure of the MTJ.

In human muscle the concentration of integrin type $\alpha 7 \beta 1$ increases following eccentric exercise (De Lisio et al., 2015). This integrin is also located at the MTJ, and because integrins are responsible for direct force transmission from muscle to tendon, increasing levels may be a way to prepare MTJ for increasing stress (Boppart et al., 2006). Similarly, in mice a single session of multiple eccentric contractions induces a significant increase of vinculin and talin in the soleus and plantaris muscles. Similar results are found in rats exposed to running with a higher expression of the mRNA for vinculin (Curzi et al., 2016). Although these proteins are found in the MTJ, they are not exclusively seen in this region, indicating that the increase in expression following exercise could arise from different regions of the muscle. Like the MTJ, both the neuromuscular junction and the costameres involved in lateral force transmission contain vinculin (Pardo et al., 1983; Ervasti, 2003). Both studies analyzed whole muscles and parts of tendon meaning that the increases in 


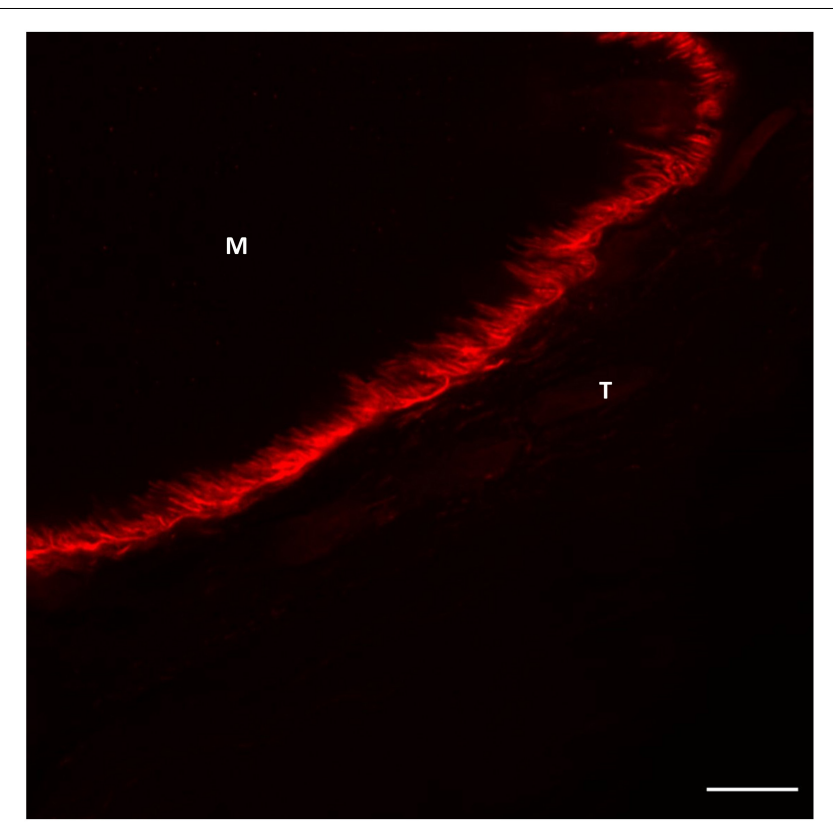

FIGURE 2 | Confocal image of human semitendinosus MTJ showing the highly folded muscle membrane at the interface between muscle $(\mathrm{M})$ and tendon (T). Collagen XXII labeling (red) the foldings connecting the tendon (T) with the muscle (M) The nuclei are stained blue (DAPI). Scale bar is $10 \mu \mathrm{m}$. For staining protocol and details regarding image acquisition (see Supplementary File).

vinculin and talin are not necessarily seen at the MTJ. However, these two proteins are known to be present to a high extent at the MTJ but also neuromuscular junction, meaning that the increase following exercise is likely to arise from the MTJ where they are both elements in the chain of proteins that are responsible for force transmission through the junction (Frenette and Côté, 2000). Increase in expression of vinculin was also observed in rats exposed to a running intervention. However, it is not known if the increased levels of these proteins after exercise result in strengthening of the MTJ. It could be expected that the amount of larger collagens in the human MTJ would increase following heavy resistance exercise, but this has not been demonstrated for collagen I, III and VI (Jakobsen et al., 2018). However, the FACIT collagen type XIV increases in the endomysium surrounding the muscle fibers closest to the MTJ following exercise (Jakobsen et al., 2017). Like the MTJ, the endomysium contains a wide variety of collagens, and collagen XIV might be responsible for anchoring the larger collagen fibrils to form stronger networks.

The effects of various exercises on the length of the distal sarcomere in rat MTJs have been studied. Whether these lengths are important for the MTJ and risk of injury is unknown. Theoretically shorter sarcomere length, not to be confused with fascicle length, would be beneficial at the MTJ since they are more resistant to stretch during heavy loading, due to more overlapping cross-bridges between actin and myosin (Morgan et al., 1991; Rassier et al., 2020). In rats exposed to swimming exercise the distal sarcomeres of the sternomastoid MTJ are significantly shorter than in resting control rats (Jacob et al., 2019). However, the opposite is found following the same exercise intervention in rats of similar age, in the soleus muscle (Rissatto Sierra et al., 2018). So, there is conflicting evidence.

Following loaded and unloaded ladder exercise the distal sarcomere of rat soleus muscle is found to be shorter than in control rats. In contrast, the distal sarcomere from the plantaris muscle from the same animal is longer compared to control rats (Rocha et al., 2020). Whether the inhomogeneous effects of exercise on the length of the distal sarcomere at the MTJ is due to differences in the exercise regimens used, or that different muscles are loaded differently during the exercises, is not known. Future research is needed, preferably with the use of eccentric exercise as the chosen exercise modality since this is what has been shown to have a positive effect on the risk of strain injury (as discussed in detail later). Results from each animal or person should be pooled before statistical analysis of group values (instead of pooling all results in the groups). Finally, the person analyzing data should be blinded to the intervention. In a number of earlier studies (Kannus et al., 1992; Tidball and Quan, 1992; Zamora et al., 1995; Kojima et al., 2008; Curzi et al., 2012, 2013, 2016; Rissatto Sierra et al., 2018; Jacob et al., 2019; Pimentel et al., 2020) there is no certainty that data have been acquired after such basic principles.

\section{CELL TURNOVER}

The MTJ is not a resting structure. There is a very high rate of remodeling in the muscle fibers near the MTJ (Jakobsen et al., 2018). Approximately half of the fibers adjacent to the MTJ contain one or more centralized nuclei and stain positive for the Neural Cell Adhesion Molecule (NCAM), indicating remodeling or formation of new muscle fibers (Figure 4A; Jamali et al., 2000; Chargé and Rudnicki, 2004). Contrary, in the muscle belly only a small percentage of the muscle fibers contain centralized nuclei (Dreyer et al., 2006). Even in muscles that have not exercised, almost $50 \%$ of the fibers at the MTJ contain centralized nuclei, indicating extensive remodeling in this area. On cross-section images the increased proportion of fibers with centralized nuclei normalizes just few fibers from the MTJ. Similarly, longitudinal sections have shown that the same muscle fiber has a higher expression of NCAM at its distal end near the MTJ compared to further from the MTJ, suggesting regional differences in protein expression across the same muscle fiber (Figure 4B). This remodeling involves different cell types, including satellite cells, fibroblasts and macrophages (Murphy et al., 2011; Bentzinger et al., 2013).

Satellite cells surround the periphery of resting muscle fibers, ready to be activated. Upon activation, they proliferate into daughter cells that can be donated as new myonuclei or fuse to form new myotubes. In skeletal muscles, satellite cells proliferate when muscles are exposed to resistance exercise (Kadi and Thornell, 2000), and even a single exercise session is enough to induce this (Bellamy et al., 2014). However, the high rate of remodeling at the MTJ is not associated with a concomitant increase in concentrations of satellite cells. In fact, the number of satellite cells near MTJ is the same as in muscle tissue far from 


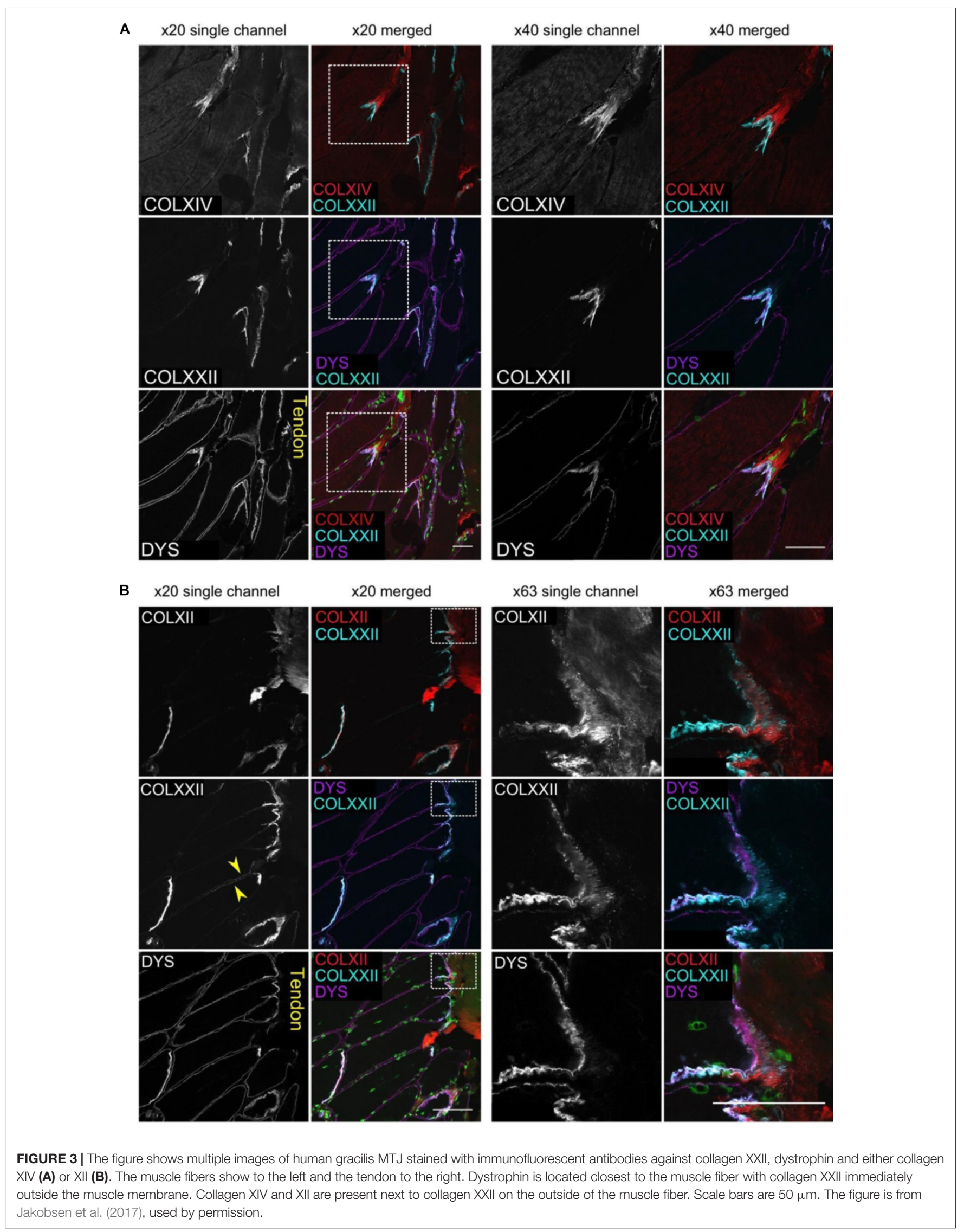




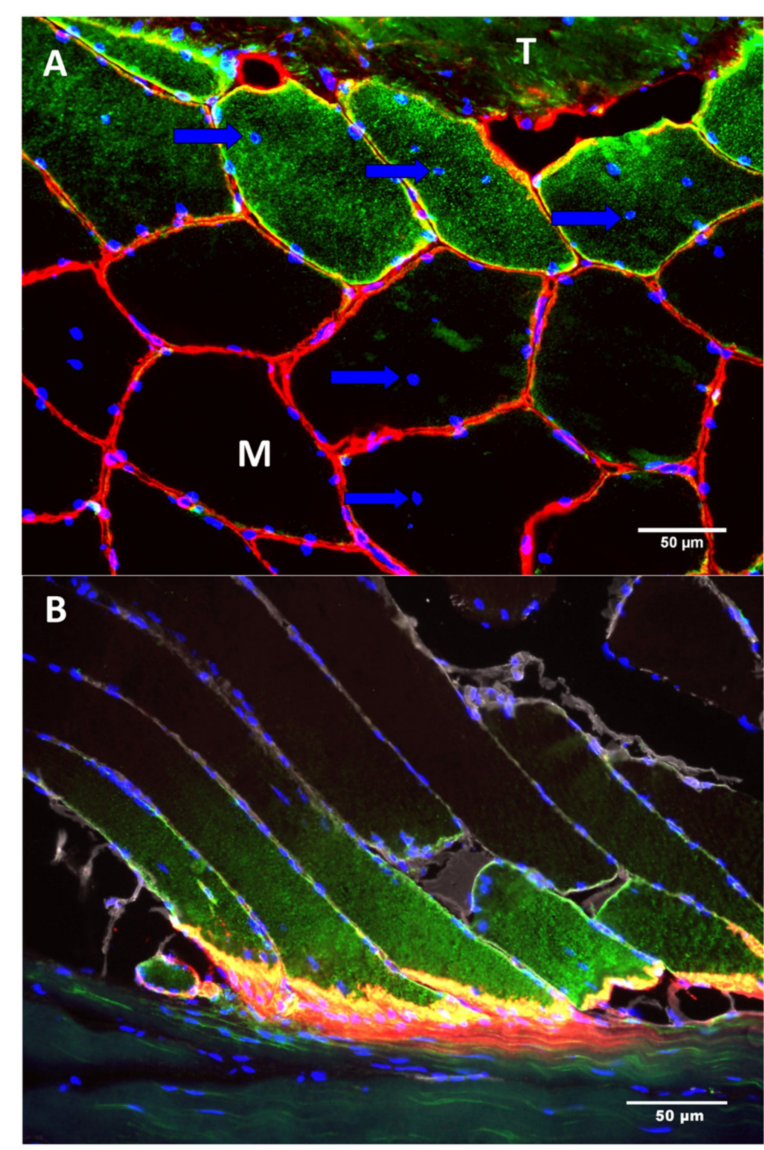

FIGURE 4 | The figure shows two sections (A,B) of a human semitendinosus muscle stained for NCAM (green), collagen IV (red) and DAPI (Blue-indicating the nuclei). (A) In the top of the image there is tendon (T) and below is the muscle (M). The muscle fibers located closest to the tendon express signs of remodeling by containing centralized myonuclei (arrow) as well as NCAM(CD5S6) staining of the cytoplasm. (B) As the muscle fibers approach the MTJ the immunoreactivity of NCAM increases whereas no staining is seen in the fibers in the upper part of the image, farthest from the MTJ. Scale bar is $50 \mu \mathrm{m}$. Images are reprinted with permission from Jakobsen et al. (2018).

the MTJ, and the concentration of satellite cells is unaffected by 4 weeks resistance exercise (Jakobsen et al., 2018). This indicates that satellite cells at the MTJ respond differently than those in muscle. However, it could be a dynamic phenomenon: the extremely high rate of remodeling at the MTJ could initiate a high demand for satellite cells, and the resulting, newly formed daughter cells could fuse immediately with a muscle fiber. If this is the case, the increase in the satellite cell pool will not show in a static cell count. However, additional studies are needed to fully understand the dynamics of satellite cells at the MTJ. While satellite cells have been shown to be detrimental for optimal muscle regeneration and repair they are not the only cell type involved (Joe et al., 2010; Sambasivan et al., 2011; Wang and Rudnicki, 2012). Inflammatory cells, such as macrophages and neutrophils, participate in this complex process, as well as fibroblasts (Toumi et al., 2006; Tidball and Villalta, 2010). Interestingly, fibro-adipogenic cells (FAPs)
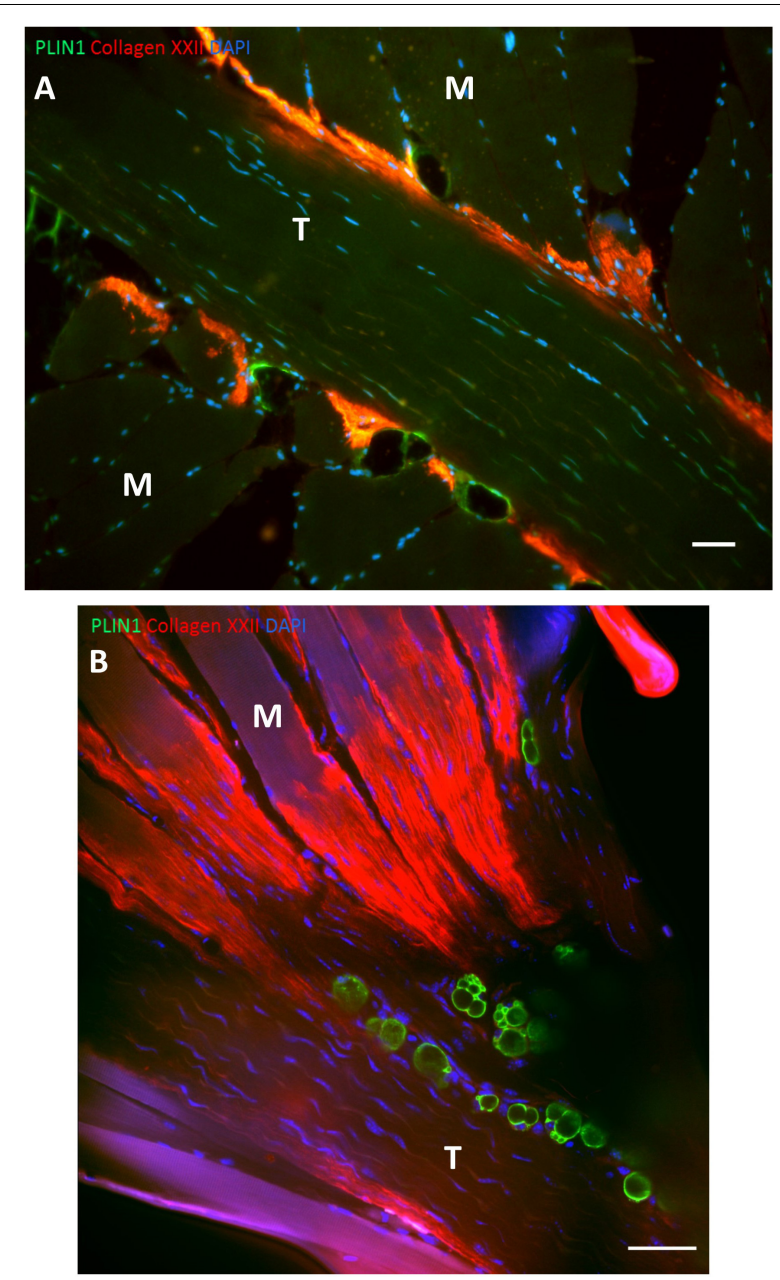

FIGURE 5 | Adipocytes at human and mouse MTJ's. (A) The figure shows a section from human semitendinosus muscle with the tendon $(T)$ in the middle and the muscle fibers (M) approaching from both sides. The MTJ is identified by collagen XXII immunofluorescent staining (red) and the adipocytes are stained with PLIN1 (green), and nuclei are stained with DAPI (blue). Adipocytes are located very close to the MTJ. Scale bar is $50 \mu \mathrm{m}$. (B) Mouse soleus MTJ in confocal microscopy showing adipocytes (PLIN = green) and collagen XXII indicating the MTJ (red). Scale bar is $50 \mu \mathrm{m}$. Images are reprinted with permission from Jakobsen et al. (2020).

which are the precursor cells for fibroblasts and adipocytes, have been shown to be important for myogenic proliferation following muscle injury (Joe et al., 2010; Heredia et al., 2013; Biferali et al., 2019).

It has recently been demonstrated that adipocytes exist in high numbers in close relation to the MTJ in humans and mice (Figure 5; Jakobsen et al., 2020). Adipocytes in skeletal muscle is normally a sign of poor muscle function and insulin resistance (Vettor et al., 2009), but at the MTJ adipocytes are present in healthy humans and animals. The MTJ has previously been reported to contain a high mitochondrial content indicating an increased oxidative phosphorylation but since the adipocytes are located extracellularly, they might not be involved in the energy metabolism of the muscle fibers (Eisenberg and Milton, 1984). 
However, since adipocytes are known to be capable of producing various cytokines involved in numerous processes throughout the body (Ronti et al., 2006), they may play a role in the highly active remodeling process at the MTJ or in the regeneration following injury.

The regeneration and repair following muscle strain injury is a complex process which is not fully understood yet. However, following injury there is a rapid increase in inflammatory cells, macrophages and neutrophils (Butterfield et al., 2006). Macrophages initially enter the injured region as pro-inflammatory M1 macrophages, capable of phagocytosis and secretion of pro-inflammatory cytokines. As they decline in concentration, the anti-inflammatory M2 macrophages increase to aid in the repair of the injured tissue (St. Pierre and Tidball, 1994). By secreting cytokines, e.g., platelet derived growth factor (PDGF) macrophages activate fibroblasts, thereby ensuring a restoration of the ECM and formation of fibrosis (Kovacs and Dipietro, 1994). Without proper coordination between the macrophages, fibroblasts and satellite cells, optimal restoration of the tissue cannot be accomplished resulting in excessive formation of fibrosis and impaired muscle function. In skin lesions the interplay between adipocytes and fibroblasts is important for optimal healing (Schmidt and Horsley, 2013). This has not been confirmed in muscle yet, but the presence of adipocytes at the MTJ and the finding of cytokines involved in adipogenesis in the exudate of human MTJ following injury, suggests a prominent role for this cell-type in the repair of the MTJ (Bayer et al., 2019).

\section{STRAIN INJURIES}

Muscle injuries can be classified as either direct or indirect. The most common indirect type is the strain injury, defined as a muscular trauma affecting the tissue structure with various degree of tear (Mueller-Wohlfahrt et al., 2013). Strain injuries are among the most common injuries in a wide range of sports affecting various muscles (Orchard and Seward, 2002; Ekstrand et al., 2011; Opar et al., 2014; Ishøi et al., 2019). They are most dominantly located at the MTJ and show as small disruptions and edema between the muscle and tendon on ultrasound and MRI imaging (De Smet et al., 1990; De Smet and Best, 2000).

Muscles which are often exposed to rapid stretch during powerful movements, such as the hamstrings, rectus femoris, hipadductor and calf muscles, are most susceptible to strain injury (Ekstrand et al., 2011; Eckard et al., 2017; Green and Pizzari, 2017; Green et al., 2020; Hultman et al., 2020). Generally, these injuries occur during activities where the muscle is either passively overstretched or during fast eccentric contractions where the MTJ is exposed to high loads during lengthening (Askling et al., 2008; Danielsson et al., 2020; Huygaerts et al., 2020).

In the hamstring muscles two types of injury mechanisms have been identified: the stretch-type injury and sprinting-type injury. The stretch-type commonly occurs during kicking activities or when the hip is flexed while the leg is stretched, for example during pick-up of a ball in American type football (Hagel, 2005). The sprint-type injury is named after its occurrence during sprinting, and it mostly affects the proximal part of the biceps femoris long head (Ekstrand et al., 2011; Fiorentino et al., 2014; Huygaerts et al., 2020). It is suggested that the late swing phase and the early stance phase is when the hamstrings are subjected to the highest loads during running (Chumanov et al., 2011; Schache et al., 2012; Fiorentino et al., 2014). During these phases the hamstring muscles are stretched while contracting rapidly.

Similar to the hamstring strain injuries both rectus femoris and adductor longus injuries are frequently seen during kicking and sprinting activities where the muscles are exposed to rapid stretch while contracting affecting athletes in multiple disciplines where kicking and sprinting activities are involved (Mendiguchia et al., 2013; Serner et al., 2015, 2019). Strain injury to the calf muscles, "Tennis-Leg," is seen in the medial head of gastrocnemius as well as the soleus, probably depending on injury mechanism (Delgado et al., 2002; Green et al., 2020). The mechanism of tennis leg has not been fully elucidated, but it is thought to occur during the late stance phase in sprinting activities where the knee is extended while a strong plantar flexion is performed by the gastrocnemius (Orchard et al., 2002).

Eccentric contractions can potentially cause muscle damage due to stretching of the sarcomeres, leading to fewer connections between actin and myosin and a suboptimal length-tension relationship (Gordon et al., 1966; Morgan, 1990; Dueweke et al., 2017). However, a large force production itself is not sufficient to induce strain injury in otherwise healthy MTJ (Lieber and Friden, 1993; Garrett, 1996). This indicates that in addition to a strong contraction of the sarcomeres, a forceful pull on the muscle provided by the tendon is needed to create a strain injury where the strength of the adhesion between these two tissues is exceeded. This is also the case in the previously described injury mechanisms for the most frequent strain injuries where a rapid stretch is seen together with a strong muscle contraction. Experimentally induced strain injuries in animal muscles, where the muscles are pulled while stimulated to contract, have shown that a disruption occurs either in the distal part of the muscle fibers or at the basal lamina between the muscle fiber and tendon (Tidball, 1984; Tidball and Chan, 1989), confirming that the connection between the muscle fibers and the tendon is the "weak-spot." Unfortunately, a histologic description of a strain injury has not yet been published for humans.

\section{PREVENTION OF HAMSTRING STRAIN INJURIES}

A recent review has summarized the current knowledge regarding diagnosis, prevention and treatment of the most common strain injuries (Ishøi et al., 2019). Therefore, the current review will focus on prevention of hamstring strain injuries, for which there is the best evidence.

Hamstring strain injuries are among the most frequent noncontact injuries in sports involving high speed running such as football, Australian rules football and athletics (Orchard and Seward, 2002; Ekstrand et al., 2011; Opar et al., 2014). It is the most common reason for inability to participate in sports. The pathogenesis of these injuries, the risk factors and possible 
prevention strategies have been subject for several recent studies (Mjolsnes et al., 2004; Petersen et al., 2011; Seagrave et al., 2014; Van Der Horst et al., 2015; Bourne et al., 2017). Low eccentric strength has been proposed as a risk factor for hamstring strain injury as well as short fascicle length, low hamstring to quadriceps strength ratio, hamstring tightness, muscle fatigue, poor warmup, previous hamstring strain and age among others (Mair et al., 1996; Petersen, 2005; Opar et al., 2015; Timmins et al., 2016).

The role of muscle fatigue and fascicle length in relation to strain injury has not been fully elucidated. In a mechanistic study of strain injury, in which rabbit muscles were stretched while either being stimulated to induce contraction or left unstimulated, the stimulated muscles could produce $15 \%$ more force at failure, while the absorbed energy was 100\% greater than in the unstimulated state. This suggests that muscle contractions affect the ability of the passive components to absorb force in the muscle fibers, i.e., the connective tissue (Garrett, 1996). Therefore, any condition that affects the muscle ability of the fibers to activate optimally, such as fatigue or weakness, would tend to increase the risk of injury (Mair et al., 1996). This might also explain why greater fascicle lengths are protective against strain injury since longer fascicles are capable of providing maximum force at a greater muscle length and higher velocity, meaning they are more resistant to rapid stretch (Bodine et al., 1982; Lieber and Fridén, 2000). This resistance to stretch means that fewer sarcomeres are disrupted during eccentric contractions leading to an unaffected force production and thereby an increased energy absorption from the passive structures surrounding the muscle fibers. Eccentric exercise training has been shown to increase fascicle length by adding sarcomeres in series (Lynn and Morgan, 1994), however, this has been questioned in a very recent study where there was no addition of sarcomeres in human biceps femoris muscle following 3 weeks of Nordic Hamstring exercise (Pincheira et al., 2021). Therefore, it is not clear what the mechanism behind the lengthening of the fascicles is. In addition, to induce lengthening of fascicles eccentric exercise also increases eccentric hamstring strength. Many exercise interventions have focused on eccentric exercise in the prevention of strain injuries with the Nordic Hamstring protocol being the most widely used (Askling et al., 2003; Mjolsnes et al., 2004; Arnason et al., 2008; Petersen et al., 2011; Van Der Horst et al., 2015; Bourne et al., 2018).

The original Nordic Hamstring protocol consisted of the eccentric exercise, Nordic Hamstring, periodized with increasing volume over 10 weeks (Mjolsnes et al., 2004). The Nordic Hamstring protocol reduce the incidence of hamstring strain injuries by up to 51\% (Al Attar et al., 2017). The clinical effect of this type of exercise is probably due to its effects on many of the previously mentioned risk factors for strain injury. Besides increasing hamstring strength (and thereby also improving hamstring to quadriceps strength ratio) it increases the length of fascicles and probably also eccentric hamstring strength capacity (Mjolsnes et al., 2004; Bourne et al., 2017; Ishøi et al., 2018; Presland et al., 2018; Ribeiro-Alvares et al., 2018;
Duhig et al., 2019; Pollard et al., 2019; Siddle et al., 2019; Whyte et al., 2019; Medeiros et al., 2020).

Future studies looking at hamstring strain injury prevention should focus on the implementation of the Nordic Hamstring protocol. Among the 32 best football clubs in Europe and 18 clubs from the Norwegian Tippeliga (where the Nordic Hamstring protocol was developed) only $10 \%$ of the clubs were compliant in 2015 with the Nordic Hamstring protocol (Bahr et al., 2015). A recent study described that athletes didn't want to do Nordic Hamstring due to fear that they would be too sore thereby affecting their other training (Chesterton et al., 2020). This is important to address in future studies. In on our previous research we have used the Nordic Hamstring exercise on patients with anterior cruciate ligament rupture in the study of the MTJ (Jakobsen et al., 2017). Our clinical experience is that the Nordic Hamstring protocol is easily implemented, even in subjects with a low activity level, and the Delayed Onset Muscle Soreness (DOMS) rarely occur after the first couple of sessions. Therefore, the strategy to implement the Nordic Hamstring protocol in an athletic setting (Arnason et al., 2008; Petersen et al., 2011), where it is used more intensively off-season to build up strength and tolerance and less intensively in-season, seems logical.

In addition to the clinical focus on the implementation of prophylactic training, future human studies can increase our understanding of the tissue mechanisms, which besides changes in fascicle length include for instance alterations in the surface area of the MTJ and changes in the concentration of specific proteins involved in adaption of the MTJ following eccentric training. This has been explored to some extent in rats and mice, showing increases in the surface area of MTJ and concentrations of structural proteins (vinculin, talin and collagen XIV) at the MTJ following exercise (Frenette and Côté, 2000; Roffino et al., 2006; Kojima et al., 2008; Curzi et al., 2012), but it has only been sparsely studied in humans (Jakobsen et al., 2017). A deeper understanding of the effects of eccentric exercise on the MTJ at the molecular and ultrastructural level is a necessary evidence base for introducing new effective methods to prevent strain injuries.

\section{PERSPECTIVES}

Knowledge about the human MTJ is limited. There is no standard method to obtain percutaneous biopsies from MTJ. Since the MTJ consists of two different tissues, muscle and tendon, it is necessary technically to separate samples into muscle, MTJ and tendon to investigate the metabolism in this region, and currently there is no reliable method to do this. Once these methodological challenges have been overcome, structured research in the human MTJ can be performed as basis for an understanding of strain injuries and their prevention. With the current knowledge candidate explanations of how MTJ may adapt to eccentric training are: by increasing fascicle length, increasing the surface area between muscle and tendon through enlargement of foldings, increasing concentration of structural 
proteins of importance for force transmission between tissues, such as dystrophin, integrins, and collagens, and increasing the lateral force transmission through the costameres. Also, in the future the interplay between macrophages, satellite cells, fibroblasts and adipocytes in the coordination of remodeling following exercise, injury and inactivity should be studied.

\section{WHAT IS ALREADY KNOWN}

The myotendinous junction (MTJ) is the interface between muscle and tendon and where force is transmitted between the two tissues. It is also a common location for strain injuries in sports. Most of these can be prevented by heavy eccentric exercise.

\section{WHAT ARE THE NEW FINDINGS}

The surface area between muscle and tendon is increased by foldings of tendon into muscle, and this reduces stress between the tissues. In animals, the size and number of foldings are increased as a response to heavy training and reduced during inactivity. In humans, the muscle fibers near the MTJ show very high rates of remodeling compared to other regions of the muscle. Adipocytes are seen in high number at MTJ and might be important for the adaption of MTJ to various loading conditions.

\section{REFERENCES}

Al Attar, W. S. A., Soomro, N., Sinclair, P. J., Pappas, E., and Sanders, R. H. (2017). Effect of Injury Prevention Programs that Include the Nordic Hamstring Exercise on Hamstring Injury Rates in Soccer Players: A Systematic Review and Meta-Analysis. Sport. Med. 47, 907-916. doi: 10.1007/s40279-016-0638-2

Arnason, A., Andersen, T. E., Holme, I., Engebretsen, L., and Bahr, R. (2008). Prevention of hamstring strains in elite soccer: an intervention study. Scand J. Med. Sci. Sport 18, 40-48. doi: 10.1111/j.1600-0838.2006.00634.x

Askling, C., Karlsson, J., and Thorstensson, A. (2003). Hamstring injury occurrence in elite soccer players after preseason strength training with eccentric overload. Scand. J. Med. Sci. Sport 13, 244-250. doi: 10.1034/j.1600-0838.2003.00312.x

Askling, C. M., Tengvar, M., Saartok, T., and Thorstensson, A. (2008). Proximal hamstring strains of stretching type in different sports: Injury situations, clinical and magnetic resonance imaging characteristics, and return to sport. Am. J. Sports Med. 36, 1799-1804. doi: 10.1177/0363546508315892

Bahr, R., Thorborg, K., and Ekstrand, J. (2015). Evidence-based hamstring injury prevention is not adopted by the majority of Champions League or Norwegian Premier League football teams: The Nordic Hamstring survey. Br. J. Sports Med. 49, 1466-1471. doi: 10.1136/bjsports-2015-094826

Bayer, M. L., Bang, L., Hoegberget-Kalisz, M., Svensson, R. B., Olesen, J. L., Karlsson, M. M., et al. (2019). Muscle-strain injury exudate favors acute tissue healing and prolonged connective tissue formation in humans. FASEB J. 33, 10369-10382. doi: 10.1096/fj.201900542R

Bellamy, L. M., Joanisse, S., Grubb, A., Mitchell, C. J., McKay, B. R., Phillips, S. M., et al. (2014). The Acute Satellite Cell Response and Skeletal Muscle Hypertrophy following Resistance Training. PLoS One 9:e109739. doi: 10.1371/journal.pone. 0109739

Bengtsson, H., Ekstrand, J., Waldén, M., and Hägglund, M. (2019). Few training sessions between return to play and first match appearance are associated with an increased propensity for injury: a prospective cohort study of male professional football players during 16 consecutive seasons. Br. J. Sports Med. 2019:100655. doi: 10.1136/bjsports-2019-100655

\section{AUTHOR CONTRIBUTIONS}

Both authors contributed to the planning, writing, and editing of the manuscript.

\section{FUNDING}

We were supported by Copenhagen University Hospital, Bispebjerg and Frederiksberg, the International Olympic Committee as well as the Aase and Einar Danielsens foundation.

\section{ACKNOWLEDGMENTS}

A special thanks to Abigail Mackey and Michael Kjaer for valuable inputs and discussions about the human MTJ. We also acknowledge the Core Facility for Integrated Microscopy, Faculty of Health and Medical Sciences, and University of Copenhage where the confocal and electron microscopy images are captured.

\section{SUPPLEMENTARY MATERIAL}

The Supplementary Material for this article can be found online at: https://www.frontiersin.org/articles/10.3389/fphys. 2021.635561/full\#supplementary-material

Bentzinger, C. F., Wang, Y. X., Dumont, N. A., and Rudnicki, M. A. (2013). Cellular dynamics in the muscle satellite cell niche. EMBO Rep. 14, 1062-1072. doi: 10.1038/embor.2013.182

Biferali, B., Proietti, D., Mozzetta, C., and Madaro, L. (2019). Fibro-Adipogenic Progenitors Cross-Talk in Skeletal Muscle: The Social Network. Front. Physiol. 10:01074. doi: 10.3389/fphys.2019.01074

Bodine, S. C., Roy, R. R., Meadows, D. A., Zernicke, R. F., Sacks, R. D., Fournier, M., et al. (1982). Architectural, histochemical, and contractile characteristics of a unique biarticular muscle: The cat semitendinosus. J. Neurophysiol. 48, 192-201. doi: 10.1152/jn.1982.48.1.192

Boppart, M. D., Burkin, D. J., and Kaufman, S. J. (2006). Alpha7beta1-integrin regulates mechanotransduction and prevents skeletal muscle injury. Am. J. Physiol. Cell Physiol. 290, C1660-C1665. doi: 10.1152/ajpcell.00317.2005

Bourne, M. N., Duhig, S. J., Timmins, R. G., Williams, M. D., Opar, D. A., Al Najjar, A., et al. (2017). Impact of the Nordic hamstring and hip extension exercises on hamstring architecture and morphology: Implications for injury prevention. $\mathrm{Br}$. J. Sports Med. 51, 469-477. doi: 10.1136/bjsports-2016-096130

Bourne, M. N., Timmins, R. G., Opar, D. A., Pizzari, T., Ruddy, J. D., Sims, C., et al. (2018). An Evidence-Based Framework for Strengthening Exercises to Prevent Hamstring Injury. Sport. Med. 48, 251-267. doi: 10.1007/s40279-017-0796-x

Butterfield, T. A., Best, T. M., and Merrick, M. A. (2006). The dual roles of neutrophils and macrophages in inflammation: A critical balance between tissue damage and repair. J. Athl. Train. 41, 457-465. doi: 10.1016/s0162-0908(08) 79217-1

Chargé, S. B. P., and Rudnicki, M. A. (2004). Cellular and molecular regulation of muscle regeneration. Physiol. Rev. 84, 209-238. doi: 10.1152/physrev.00019. 2003

Charvet, B., Guiraud, A., Malbouyres, M., Zwolanek, D., Guillon, E., Bretaud, S., et al. (2013). Knockdown of col22al gene in zebrafish induces a muscular dystrophy by disruption of the myotendinous junction. Development 140 , 4602-4613. doi: 10.1242/dev.096024

Charvet, B., Malbouyres, M., Pagnon-Minot, A., Ruggiero, F., and Le Guellec, D. (2011). Development of the zebrafish myoseptum with emphasis on the 
myotendinous junction. Cell Tissue Res. 346, 439-449. doi: 10.1007/s00441011-1266-7

Charvet, B., Ruggiero, F., and Le Guellec, D. (2012). The development of the myotendinous junction. A Rev. Muscles Ligaments Tendons J. 2, 53-63.

Chesterton, P., Tears, C., Wright, M., and Portas, M. (2020). Hamstring injury prevention practices and compliance of the Nordic hamstring program in English professional football. Transl. Sport. Med. 2020:tsm2.209. doi: 10.1002/ tsm2.209

Chumanov, E. S., Heiderscheit, B. C., and Thelen, D. G. (2011). Hamstring musculotendon dynamics during stance and swing phases of highspeed running. Med. Sci. Sports Exerc. 43, 525-532. doi: 10.1249/MSS. 0b013e3181f23fe 8

Curzi, D., Lattanzi, D., Ciuffoli, S., Burattini, S., Grindeland, R. E., Edgerton, V. R., et al. (2013). Growth hormone plus resistance exercise attenuate structural changes in rat myotendinous junctions resulting from chronic unloading. Eur. J. Histochem. 57:e37. doi: 10.4081/ejh.2013.e37

Curzi, D., Salucci, S., Marini, M., Esposito, F., Agnello, L., Veicsteinas, A., et al. (2012). How physical exercise changes rat myotendinous junctions: an ultrastructural study. Eur. J. Histochem. 56:e19. doi: 10.4081/ejh.2012.19

Curzi, D., Sartini, S., Guescini, M., Lattanzi, D., Di Palma, M., Ambrogini, P., et al. (2016). Effect of Different Exercise Intensities on the Myotendinous Junction Plasticity. PLoS One 11:e0158059. doi: 10.1371/journal.pone.0158059

Danielsson, A., Horvath, A., Senorski, C., Alentorn-Geli, E., Garrett, W. E., Cugat, R., et al. (2020). The mechanism of hamstring injuries- A systematic review. BMC Musculoskelet. Disord 21, 3658-3658. doi: 10.1186/s12891-02003658-8

De Lisio, M., Farup, J., Sukiennik, R. A., Clevenger, N., Nallabelli, J., Nelson, B., et al. (2015). The acute response of pericytes to muscle-damaging eccentric contraction and protein supplementation in human skeletal muscle. J. Appl. Physiol. 119, 900-907. doi: 10.1152/japplphysiol.01112.2014

De Smet, A. A., and Best, T. M. (2000). MR imaging of the distribution and location of acute hamstring injuries in athletes. AJR. Am. J. Roentgenol. 174, 393-399. doi: 10.2214/ajr.174.2.1740393

De Smet, A. A., Fisher, D. R., Heiner, J. P., and Keene, J. S. (1990). Magnetic resonance imaging of muscle tears. Skeletal Radiol. 19, 283-286. doi: 10.1007/ BF00191673

Delgado, G. J., Chung, C. B., Lektrakul, N., Azocar, P., Botte, M. J., Coria, D., et al. (2002). Tennis leg: Clinical US study of 141 patients and anatomic investigation of four cadavers with MR imaging and US. Radiology 224, 112-119. doi: 10. 1148/radiol.2241011067

Dreyer, H. C., Blanco, C. E., Sattler, F. R., Schroeder, E. T., and Wiswell, R. A. (2006). Satellite cell numbers in young and older men 24 hours after eccentric exercise. Muscle Nerve 33, 242-253. doi: 10.1002/mus.20461

Dueweke, J. J., Awan, T. M., and Mendias, C. L. (2017). Regeneration of skeletal muscle after eccentric injury. J. Sport Rehabil. 26, 171-179. doi: 10.1123/jsr. 2016-0107

Duhig, S. J., Bourne, M. N., Buhmann, R. L., Williams, M. D., Minett, G. M., Roberts, L. A., et al. (2019). Effect of concentric and eccentric hamstring training on sprint recovery, strength and muscle architecture in inexperienced athletes. J. Sci. Med. Sport 22, 769-774. doi: 10.1016/j.jsams.2019.01.010

Eckard, T. G., Padua, D. A., Dompier, T. P., Dalton, S. L., Thorborg, K., and Kerr, Z. Y. (2017). Epidemiology of Hip Flexor and Hip Adductor Strains in National Collegiate Athletic Association Athletes, 2009/2010-2014/2015. Am. J. Sports Med. 45, 2713-2722. doi: 10.1177/0363546517716179

Eisenberg, B. R., and Milton, R. L. (1984). Muscle fiber termination at the tendon in the frog's sartorius: A stereological study. Am. J. Anat. 171, 273-284. doi: 10.1002/aja.1001710304

Ekstrand, J., Hägglund, M., and Waldén, M. (2011). Injury incidence and injury patterns in professional football: The UEFA injury study. Br. J. Sports Med. 45, 553-558. doi: 10.1136/bjsm.2009.060582

Ervasti, J. M. (2003). Costameres: The Achilles' heel of Herculean muscle. J. Biol. Chem. 278, 13591-13594. doi: 10.1074/jbc.R200021200

Fiorentino, N. M., Rehorn, M. R., Chumanov, E. S., Thelen, D. G., and Blemker, S. S. (2014). Computational models predict larger muscle tissue strains at faster sprinting speeds. Med. Sci. Sports Exerc. 46, 776-786. doi: 10.1249/MSS. 0000000000000172
Frenette, J., and Côté, C. H. (2000). Modulation of structural protein content of the myotendinous junction following eccentric contractions. Int. J. Sports Med. 21, 313-320. doi: 10.1055/s-2000-3774

Garrett, W. Jr. (1996). Muscle strain injuries. Am. J. Sport Med. 1996, 2-8.

Garrett, W. E., Califf, J. C., and Bassett, F. H. (1984). Histochemical correlates of hamstring injuries. Am. J. Sports Med. 12, 98-103. doi: 10.1177/ 036354658401200202

Gordon, A. M., Huxley, A. F., and Julian, F. J. (1966). The variation in isometric tension with sarcomere length in vertebrate muscle fibres. J. Physiol. 184, 170-192. doi: 10.1113/jphysiol.1966.sp007909

Green, B., Lin, M., Schache, A. G., McClelland, J. A., Semciw, A. I., Rotstein, A., et al. (2020). Calf muscle strain injuries in elite Australian Football players: A descriptive epidemiological evaluation. Scand. J. Med. Sci. Sport. 30, 174-184. doi: $10.1111 /$ sms.13552

Green, B., and Pizzari, T. (2017). Calf muscle strain injuries in sport: A systematic review of risk factors for injury. Br. J. Sports Med. 51, 1189-1194. doi: 10.1136/ bjsports-2016-097177

Guo, C., Willem, M., Werner, A., Raivich, G., Emerson, M., Neyses, L., et al. (2006). Absence of alpha 7 integrin in dystrophin-deficient mice causes a myopathy similar to Duchenne muscular dystrophy. Hum. Mol. Genet. 15, 989-998. doi: $10.1093 / \mathrm{hmg} / \mathrm{ddl} 018$

Hagel, B. (2005). Hamstring injuries in Australian football. Clin. J. Sport Med. 15, 400. doi: 10.1097/01.jsm.0000179227.01404.d3

Hakim, C. H., Burkin, D. J., and Duan, D. (2013). Alpha 7 integrin preserves the function of the extensor digitorum longus muscle in dystrophin-null mice. J. Appl. Physiol. 115, 1388-1392. doi: 10.1152/japplphysiol.00602.2013

Henderson, C. A., Gomez, C. G., Novak, S. M., Mi-Mi, L., and Gregorio, C. C. (2017). Overview of the muscle cytoskeleton. Compr. Physiol. 7, 891-944. doi: $10.1002 /$ cphy.c160033

Heredia, J. E., Mukundan, L., Chen, F. M., Mueller, A. A., Deo, R. C., Locksley, R. M., et al. (2013). Type 2 innate signals stimulate fibro/adipogenic progenitors to facilitate muscle regeneration. Cell 153, 376-388. doi: 10.1016/j.cell.2013. 02.053

Huijing, P. A. (1999). Muscle as a collagen fiber reinforced composite: a review of force transmission in muscle and whole limb. J Biomech. 32, 329-345.

Hultman, K., Szukics, P. F., Grzenda, A., Curriero, F. C., and Cohen, S. B. (2020). Gastrocnemius Injuries in Professional Baseball Players: An Epidemiological Study. Am. J. Sports Med. 48, 2489-2498. doi: 10.1177/0363546520938759

Huygaerts, S., Cos, F., Cohen, D. D., Calleja-González, J., Guitart, M., Blazevich, A. J., et al. (2020). Mechanisms of Hamstring Strain Injury: Interactions between Fatigue. Muscle Activ. Funct. Sports 8:65. doi: 10.3390/sports8050065

Ishøi, L., Hölmich, P., Aagaard, P., Thorborg, K., Bandholm, T., and Serner, A. (2018). Effects of the Nordic Hamstring exercise on sprint capacity in male football players: a randomized controlled trial. J. Sports Sci. 36:1409609. doi: 10.1080/02640414.2017.1409609

Ishøi, L., Krommes, K., Husted, R. S., Juhl, C. B., and Thorborg, K. (2019). Diagnosis, prevention and treatment of common lower extremity muscle injuries in sport-grading the evidence: A statement paper commissioned by the Danish Society of Sports Physical Therapy (DSSF). Br. J. Sports Med. 54:528. doi: 10.1136/bjsports-2019-101228

Jacob, C. D. S., Rocha, L. C., Neto, J. P., Watanabe, I. S., and Ciena, A. P. (2019). Effects of physical training on sarcomere lengths and muscle-tendon interface of the cervical region in an experimental model of menopause. Eur. J. Histochem. 63, 131-135. doi: 10.4081/ejh.2019.3038

Jakobsen, J. R., Jakobsen, N. R., Mackey, A. L., Knudsen, A. B., Hannibal, J., Koch, M., et al. (2020). Adipocytes are present at human and murine myotendinous junctions. Transl. Sport. Med. 2020:tsm2.212. doi: 10.1002/tsm2.212

Jakobsen, J. R., Jakobsen, N. R., Mackey, A. L., Koch, M., Kjaer, M., and Krogsgaard, M. R. (2018). Remodeling of muscle fibers approaching the human myotendinous junction. Scand. J. Med. Sci. Sports 2018:sms.13196. doi: 10.1111/ sms.13196

Jakobsen, J. R., Mackey, A. L., Knudsen, A. B., Koch, M., Kjær, M., and Krogsgaard, M. R. (2017). Composition and adaptation of human myotendinous junction and neighboring muscle fibers to heavy resistance training. Scand. J. Med. Sci. Sport 27:sms.12794. doi: 10.1111/sms.12794

Jamali, A. A., Afshar, P., Abrams, R. A., and Lieber, R. L. (2000). Skeletal muscle response to tenotomy. Muscle Nerve 23, 851-862. 
Joe, A. W. B., Yi, L., Natarajan, A., Le Grand, F., So, L., Wang, J., et al. (2010). Muscle injury activates resident fibro/adipogenic progenitors that facilitate myogenesis. Nat. Cell Biol. 12, 153-163. doi: 10.1038/ncb2015

Kadi, F., and Thornell, L. E. (2000). Concomitant increases in myonuclear and satellite cell content in female trapezius muscle following strength training. Histochem. Cell Biol. 113, 99-103.

Kannus, P., Jozsa, L., Kvist, M., Lehto, M., and Järvinen, M. (1992). The effect of immobilization on myotendinous junction: an ultrastructural, histochemical and immunohistochemical study. Acta Physiol. Scand. 144, 387-394. doi: 10. 1111/j.1748-1716.1992.tb09309.x

Knudsen, A. B., Larsen, M., Mackey, A. L., Hjort, M., Hansen, K. K., Qvortrup, K., et al. (2015). The human myotendinous junction: an ultrastructural and 3D analysis study. Scand. J. Med. Sci. Sport. 25, e116-e123. doi: 10.1111/sms. 12221

Koch, M., Schulze, J., Hansen, U., Ashwodt, T., Keene, D. R., Brunken, W. J., et al. (2004). A novel marker of tissue junctions, collagen XXII. J. Biol. Chem. 279, 22514-22521. doi: 10.1074/jbc.M400536200

Kojima, H., Sakuma, E., Mabuchi, Y., Mizutani, J., Horiuchi, O., Wada, I., et al. (2008). Ultrastructural changes at the myotendinous junction induced by exercise. J. Orthop. Sci. 13, 233-239. doi: 10.1007/s00776-008-1211-0

Kovacs, E. J., and Dipietro, L. A. (1994). Fibrogenic cytokines and connective tissue production. FASEB J. 8, 854-861. doi: 10.1096/fasebj.8.11.7520879

Lieber, R. L., and Friden, J. (1993). Muscle damage is not a function of muscle force but active muscle strain. J. Appl. Physiol. 74, 520-526. doi: 10.1152/jappl.1993. 74.2.520

Lieber, R. L., and Fridén, J. (2000). Functional and clinical significance of skeletal muscle architecture. Muscle Nerve 23, 1647-1666. doi: 10.1002/10974598(200011)23:11<1647::AID-MUS1<3.0.CO;2-M

Lynn, R., and Morgan, D. L. (1994). Decline running produces more sarcomeres in rat vastus intermedius muscle fibers than does incline running. J. Appl. Physiol. 77, 1439-1444. doi: 10.1152/jappl.1994.77.3.1439

Mair, S. D., Seaber, A. V., Glisson, R. R., and Garrett, W. E. (1996). The role of fatigue in susceptibility to acute muscle strain injury. Am. J. Sports Med. 24, 137-143. doi: 10.1177/036354659602400203

Medeiros, D. M., Marchiori, C., and Baroni, B. M. (2020). Effect of Nordic Hamstring Exercise Training on Knee Flexors Eccentric Strength and Fascicle Length: A Systematic Review and Meta-Analysis. J. Sport Rehabil. 2020, 1-10. doi: 10.1123/jsr.2019-0388

Mendiguchia, J., Alentorn-Geli, E., Idoate, F., and Myer, G. D. (2013). Rectus femoris muscle injuries in football: A clinically relevant review of mechanisms of injury, risk factors and preventive strategies. Br. J. Sports Med. 47, 359-366. doi: 10.1136/bjsports-2012-091250

Mjolsnes, R., Arnason, A., Osthagen, T., Raastad, T., and Bahr, R. (2004). A 10week randomized trial comparing eccentric vs. concentric hamstring strength training in well-trained soccer players. Scand J Med. Sci. Sport. 14, 311-317. doi: 10.1046/j.1600-0838.2003.367.x

Morgan, D. L. (1990). New insights into the behavior of muscle during active lengthening. Biophys. J. 57, 209-221. doi: 10.1016/S0006-3495(90)82524-8

Morgan, D. L., Claflin, D. R., and Julian, F. J. (1991). Tension as a function of sarcomere length and velocity of shortening in single skeletal muscle fibres of the frog. J. Physiol. 441, 719-732. doi: 10.1113/jphysiol.1991.sp018775

Mueller-Wohlfahrt, H. W., Haensel, L., Mithoefer, K., Ekstrand, J., English, B., McNally, S., et al. (2013). Terminology and classification of muscle injuries in sport: The Munich consensus statement. Br. J. Sports Med. 47, 342-350. doi: 10.1136/bjsports-2012-091448

Murphy, M. M., Lawson, J. A., Mathew, S. J., Hutcheson, D. A., and Kardon, G. (2011). Satellite cells, connective tissue fibroblasts and their interactions are crucial for muscle regeneration. Development 138, 3625-3637. doi: 10.1242/dev. 064162

Opar, D. A., Drezner, J., Shield, A., Williams, M., Webner, D., Sennett, B., et al. (2014). Acute hamstring strain injury in track-and-field athletes: A 3-year observational study at the Penn Relay Carnival. Scand. J. Med. Sci. Sports 24, e254-e259. doi: 10.1111/sms.12159

Opar, D. A., Williams, M. D., Timmins, R. G., Hickey, J., Duhig, S. J., and Shield, A. J. (2015). Eccentric hamstring strength and hamstring injury risk in Australian footballers. Med. Sci. Sports Exerc. 47, 857-865. doi: 10.1249/MSS. 0000000000000465
Orchard, J., and Seward, H. (2002). Epidemiology of injuries in the Australian Football League, seasons 1997-2000. Br. J. Sports Med. 36, 39-44. doi: 10.1136/ bjsm.36.1.39

Orchard, J. W., Alcott, E., James, T., Farhart, P., Portus, M., and Waugh, S. R. (2002). Exact moment of a gastrocnemius muscle strain captured on video. $\mathrm{Br}$. J. Sports Med. 36, 222-223. doi: 10.1136/bjsm.36.3.222

Palma, L. D., Marinelli, M., Pavan, M., and Bertoni-Freddari, C. (2011). Involvement of the muscle-tendon junction in skeletal muscle atrophy: An ultrastructural study. Rom. J. Morphol. Embryol. 52, 105-109.

Pardo, J. V., D’Angelo Siliciano, J., and Craig, S. W. (1983). A vinculin-containing cortical lattice in skeletal muscle: Transverse lattice elements ('costameres') mark sites of attachment between myofibrils and sarcolemma. Proc. Natl. Acad. Sci. U. S. A. 80, 1008-1012. doi: 10.1073/pnas.80.4.1008

Passerieux, E., Rossignol, R., Chopard, A., Carnino, A., Marini, J. F., Letellier, T., et al. (2006). Structural organization of the perimysium in bovine skeletal muscle: Junctional plates and associated intracellular subdomains. J. Struct. Biol. 154, 206-216. doi: 10.1016/j.jsb.2006.01.002

Passerieux, E., Rossignol, R., Letellier, T., and Delage, J. P. (2007). Physical continuity of the perimysium from myofibers to tendons: involvement in lateral force transmission in skeletal muscle. J. Struct. Biol. 159, 19-28. doi: 10.1016/j. jsb.2007.01.022

Petersen, J. (2005). Evidence based prevention of hamstring injuries in sport. Br. J. Sport. Med. 39, 319-323. doi: 10.1136/bjsm.2005.018549

Petersen, J., Thorborg, K., Nielsen, M. B., Budtz-Jorgensen, E., and Holmich, P. (2011). Preventive effect of eccentric training on acute hamstring injuries in men's soccer: a cluster-randomized controlled trial. Am. J. Sport Med. 39, 2296-2303. doi: 10.1177/0363546511419277

Pimentel, N. J., Rocha, L. C., Barbosa, G. K., Jacob, C., dos, S., Krause, N. W., et al. (2020). Myotendinous junction adaptations to ladder-based resistance training: identification of a new telocyte niche. Sci. Rep. 10, 70971-70976. doi: 10.1038/s41598-020-70971-6

Pincheira, P. A., Boswell, M. A., Franchi, M. V., Delp, S. L., and Lichtwark, G. A. (2021). Biceps femoris long head sarcomere and fascicle length adaptations after three weeks of eccentric exercise training. bioRxiv 2021:427202. doi: 10.1101/ 2021.01.18.427202

Polgar, J., Johnson, M. A., Weightman, D., and Appleton, D. (1973). Data on fibre size in thirty-six human muscles. An autopsy study. J. Neurol. Sci. 19, 307-318. doi: 10.1016/0022-510X(73)90094-4

Pollard, C. W., Opar, D. A., Williams, M. D., Bourne, M. N., and Timmins, R. G. (2019). Razor hamstring curl and Nordic hamstring exercise architectural adaptations: Impact of exercise selection and intensity. Scand. J. Med. Sci. Sports 29, 706-715. doi: 10.1111/sms.13381

Presland, J. D., Timmins, R. G., Bourne, M. N., Williams, M. D., and Opar, D. A. (2018). The effect of Nordic hamstring exercise training volume on biceps femoris long head architectural adaptation. Scand. J. Med. Sci. Sport. 28, 1775-1783. doi: 10.1111/sms.13085

Ramaswamy, K. S., Palmer, M. L., van der Meulen, J. H., Renoux, A., Kostrominova, T. Y., Michele, D. E., et al. (2011). Lateral transmission of force is impaired in skeletal muscles of dystrophic mice and very old rats. J. Physiol. 589, 1195-1208. doi: 10.1113/jphysiol.2010.201921

Rassier, D. E., Haeger, R., De, F., and Leite, S. (2020). Sarcomere length nonuniformities dictate force production along the descending limb of the force-length relation. London: Royal Society. doi: 10.1098/rspb.2020.2133

Ribeiro-Alvares, J. B., Marques, V. B., Vaz, M. A., and Baroni, B. M. (2018). Four Weeks of Nordic Hamstring Exercise Reduce Muscle Injury Risk Factors in Young Adults. J. Strength Cond. Res. 32, 1254-1262. doi: 10.1519/JSC. 0000000000001975

Rissatto Sierra, L., Fávaro, G., Cerri, B. R., Rocha, L. C., de Yokomizo, de Almeida, S. R., et al. (2018). Myotendinous junction plasticity in aged ovariectomized rats submitted to aquatic training. Microsc. Res. Tech. 81, 816-822. doi: 10.1002/ jemt. 23040

Rocha, L. C., Pimentel Neto, J., de Sant'Ana, J. S., Jacob, C., dos, S., Barbosa, G. K., et al. (2020). Repercussions on sarcomeres of the myotendinous junction and the myofibrillar type adaptations in response to different trainings on vertical ladder. Microsc. Res. Tech. 83, 1190-1197. doi: 10.1002/jemt. 23510 
Roffino, S., Carnino, A., Charpiot, P., and Marini, J. F. (1998). Increase in rat soleus myotendinous interface after a 14-d spaceflight. C. R. Acad. Sci. III. 321, 557-564. doi: 10.1016/s0764-4469(98)80457-5

Roffino, S., Carnino, A., Chopard, A., Mutin, M., and Marini, J. F. (2006). Structural remodeling of unweighted soleus myotendinous junction in monkey. C R Biol. 329, 172-179. doi: 10.1016/j.crvi.2006.01.008

Ronti, T., Lupattelli, G., and Mannarino, E. (2006). The endocrine function of adipose tissue: An update. Clin. Endocrinol. 64, 355-365. doi: 10.1111/j.13652265.2006.02474.x

Sambasivan, R., Yao, R., Kissenpfennig, A., van Wittenberghe, L., Paldi, A., Gayraud-Morel, B., et al. (2011). Pax7-expressing satellite cells are indispensable for adult skeletal muscle regeneration. Development 138, 3647-3656. doi: 10. 1242/dev.067587

Schache, A. G., Dorn, T. W., Blanch, P. D., Brown, N. A. T., and Pandy, M. G. (2012). Mechanics of the human hamstring muscles during sprinting. Med. Sci. Sports Exerc. 44, 647-658. doi: 10.1249/MSS.0b013e318236a3d2

Schmidt, B. A., and Horsley, V. (2013). Intradermal adipocytes mediate fibroblast recruitment during skin wound healing. Dev. 140, 1517-1527. doi: 10.1242/dev. 087593

Seagrave, R. A., Perez, L., McQueeney, S., Toby, E. B., Key, V., and Nelson, J. D. (2014). Preventive Effects of Eccentric Training on Acute Hamstring Muscle Injury in Professional Baseball. Orthop. J. Sport. Med. 2:2325967114535351. doi: $10.1177 / 2325967114535351$

Serner, A., Mosler, A. B., Tol, J. L., Bahr, R., and Weir, A. (2019). Mechanisms of acute adductor longus injuries in male football players: A systematic visual video analysis. Br. J. Sports Med. 53, 158-164. doi: 10.1136/bjsports-2018099246

Serner, A., Tol, J. L., Jomaah, N., Weir, A., Whiteley, R., Thorborg, K., et al. (2015). Diagnosis of Acute Groin Injuries: A Prospective Study of 110 Athletes. Am. J. Sports Med. 43, 1857-1864. doi: 10.1177/0363546515585123

Shear, C. R., and Bloch, R. J. (1985). Vinculin in subsarcolemmal densities in chicken skeletal muscle: localization and relationship to intracellular and extracellular structures. J. Cell Biol. 101, 240-256. doi: 10.1083/jcb.101. 1.240

Siddle, J., Greig, M., Weaver, K., Page, R. M., Harper, D., and Brogden, C. M. (2019). Acute adaptations and subsequent preservation of strength and speed measures following a Nordic hamstring curl intervention: a randomised controlled trial. J. Sports Sci. 37, 911-920. doi: 10.1080/02640414.2018.1535786

St. Pierre, B. A., and Tidball, J. G. (1994). Differential response of macrophage subpopulations to soleus muscle reloading after rat hindlimb suspension. J. Appl. Physiol. 77, 290-297. doi: 10.1152/jappl.1994.77.1.290

Tidball, J. G. (1983). The geometry of actin filament-membrane associations can modify adhesive strength of the myotendinous junction. Cell Motil. 3, 439-447. doi: $10.1002 / \mathrm{cm} .970030512$

Tidball, J. G. (1984). Myotendinous junction: Morphological changes and mechanical failure associated with muscle cell atrophy. Exp. Mol. Pathol. 40, 1-12. doi: 10.1016/0014-4800(84)90060-1

Tidball, J. G. (1991). Force transmission across muscle cell membranes. J. Biomech. 24(Suppl. 1), 43-52. doi: 10.1016/0021-9290(91)90376-x

Tidball, J. G., and Chan, M. (1989). Adhesive strength of single muscle cells to basement membrane at myotendinous junctions. J. Appl. Physiol. 67, 10631069. doi: 10.1152/jappl.1989.67.3.1063
Tidball, J. G., and Quan, D. M. (1992). Reduction in myotendinous junction surface area of rats subjected to 4-day spaceflight. J. Appl. Physiol. 73, 59-64.

Tidball, J. G., and Villalta, S. A. (2010). Regulatory interactions between muscle and the immune system during muscle regeneration. Am. J. Physiol. 298, R1173-R1187. doi: 10.1152/ajpregu.00735.2009

Timmins, R. G., Bourne, M. N., Shield, A. J., Williams, M. D., Lorenzen, C., and Opar, D. A. (2016). Short biceps femoris fascicles and eccentric knee flexor weakness increase the risk of hamstring injury in elite football (soccer): A prospective cohort study. Br. J. Sports Med. 50, 1524-1535. doi: 10.1136/ bjsports-2015-095362

Toumi, H., F'guyer, S., and Best, T. M. (2006). The role of neutrophils in injury and repair following muscle stretch. J. Anat. 208, 459-470. doi: 10.1111/j.14697580.2006.00543.x

Trotter, J. A., and Baca, J. M. (1987). A stereological comparison of the muscletendon junctions of fast and slow fibers in the chicken. Anat. Rec. 218, 256-266. doi: 10.1002/ar.1092180306

Trotter, J. A., Samora, A., and Baca, J. (1985). Three-dimensional structure of the murine muscle-tendon junction. Anat. Rec. 213, 16-25. doi: 10.1002/ar. 1092130104

Valdivia, M., Vega-Macaya, F., and Olguín, P. (2017). Mechanical control of myotendinous junction formation and tendon differentiation during development. Front. Cell Dev. Biol. 5:00026. doi: 10.3389/fcell.2017.00026

Van Der Horst, N., Smits, D. W., Petersen, J., Goedhart, E. A., and Backx, F. J. G. (2015). The Preventive Effect of the Nordic Hamstring Exercise on Hamstring Injuries in Amateur Soccer Players: A Randomized Controlled Trial. Am. J. Sports Med. 43, 1316-1323. doi: 10.1177/0363546515574057

Vettor, R., Milan, G., Franzin, C., Sanna, M., De Coppi, P., Rizzuto, R., et al. (2009). The origin of intermuscular adipose tissue and its pathophysiological implications. Am. J. Physiol. Metab. 297, E987-E998. doi: 10.1152/ajpendo. 00229.2009

Wang, Y. X., and Rudnicki, M. A. (2012). Satellite cells, the engines of muscle repair. Nat. Rev. Mol. Cell Biol. 13, 127-133. doi: 10.1038/nrm3265

Whyte, E. F., Heneghan, B., Feely, K., Moran, K. A., and O'Connor, S. (2019). The Effect of Hip Extension and Nordic Hamstring Exercise Protocols on Hamstring Strength. J. Strength Cond. Res. 1, jsc.0000000000003220. doi: 10. 1519/jsc.0000000000003220

Zamora, A. J., Carnino, A., Roffino, S., and Marini, J. F. (1995). Respective effects of hindlimb suspension, confinement and spaceflight on myotendinous junction ultrastructure. Acta Astronaut. 36, 693-706. doi: 10.1016/0094-5765(95) 00159-X

Conflict of Interest: The authors declare that the research was conducted in the absence of any commercial or financial relationships that could be construed as a potential conflict of interest.

Copyright (c) 2021 Jakobsen and Krogsgaard. This is an open-access article distributed under the terms of the Creative Commons Attribution License (CC BY). The use, distribution or reproduction in other forums is permitted, provided the original author(s) and the copyright owner(s) are credited and that the original publication in this journal is cited, in accordance with accepted academic practice. No use, distribution or reproduction is permitted which does not comply with these terms. 